\title{
Ouvidoria como instrumento de participação, controle e avaliação de políticas públicas de saúde no Brasil
}

I ${ }^{1}$ Michelle Vieira Fernandez, ${ }^{2}$ Pauline Cavalcanti, ${ }^{3}$ Domicio Sá, ${ }^{4}$ Julyana Viegas I

Resumo: As Ouvidorias Públicas representam um avanço na Administração Pública brasileira no campo da gestáo democrática. Nessa perspectiva, este artigo objetiva analisar a atuação da Ouvidoria-geral do SUS. Portanto, como a Ouvidoria-geral do Sistema Único de Saúde atua no âmbito das políticas de saúde? Para responder tal pergunta, foi realizada pesquisa documental utilizando relatórios gerenciais da Ouvidoria-Geral do SUS do Ministério da Saúde, produzidos entre 2010 e 2017. Para classificar a informação, utilizou-se como categorias de análise a participação, o controle social e a avaliação. Observou-se que a participação dos cidadáos-usuários do sistema de saúde via ouvidoria vem aumentando e consolidando-se. A Ouvidoria-Geral do Sistema Único de Saúde disponibiliza uma série de canais para a participação da cidadania, incluindo telefone e internet, que são atualmente as formas de participação mais acessadas. Instrumentos como Carta SUS, Lei de Acesso a Informação e manifestações do tipo "denúncia” permitem o exercício do controle social. A satisfação do usuário é uma vertente avaliativa pouco fomentada, demonstrando descontinuidade ou despriorização de ações nesse sentido. Assim, no campo da saúde, as ouvidorias permitem a participação cidadão, o controle social e o aprimoramento das políticas e serviços, sendo importante avançar ainda mais no seu desenvolvimento.

> Palavras-chave: Ouvidoria-Geral do Sistema Único de Saúde, Participação, Controle social, Avaliação de política, Sistema Único de Saúde.

\author{
${ }^{1}$ Universidade de Brasília. Brasília- \\ DF, Brasil (michelle.vfernandez@ \\ gmail.com). \\ ORCID: 0000-0003-0224-0991 \\ ${ }^{2}$ Instituto Aggeu Magalhães \\ / FIOCRUZ. Recife-PE, Brasil \\ (pauline.cavalcanti@gmail.com). \\ ORCID: 0000-0002-1743-2075 \\ ${ }^{3}$ Instituto Aggeu Magalhães \\ / FIOCRUZ. Recife-PE, Brasil \\ (domicio@cpqam.fiocruz.br). \\ ORCID: 0000-0001-7478-7641 \\ ${ }^{4}$ Instituto Aggeu Magalhães \\ / FIOCRUZ. Recife-PE, Brasil \\ (viegasjulyana@gmail.com). \\ ORCID: 0000-0001-7663-8893
}

Recebido em: 24/01/2020 Aprovado em: 22/05/2020 Revisado em: 05/10/2021 


\section{Introdução}

O cidadáo vem ocupando um lugar central nas democracias na atualidade. Alcançar as pessoas tornou-se um dos objetivos principais dos sistemas políticos democráticos. A democracia passou a ir além de mecanismos para escolha de governantes, assumindo a necessidade de envolver toda a sociedade nos processos políticos. Essa nova concepção democrática passa pela aproximação das políticas públicas aos cidadãos, pelo alcance das decisôes políticas a esta cidadania e pela possibilidade do controle democrático através de práticas participativas.

No cenário brasileiro, reconhece-se as necessidades de controle, regulação, análise e avaliação de políticas públicas. Há, ainda, o reconhecimento da importância do aperfeiçoamento e da inovação constantes na gestão das políticas públicas de saúde. Nesse contexto, as ouvidorias públicas e também a Ouvidoria-Geral do Sistema Único de Saúde (SUS) apresentam-se como espaços institucionais que viabilizam formas de participação da cidadania nas políticas de saúde.

Nesse contexto, o presente artigo tem como objetivo analisar a atuação da Ouvidoria-Geral do SUS a partir das vias da participação social, controle e avaliação nas políticas públicas de saúde. $\mathrm{O}$ artigo está organizado em seis partes: a primeira apresenta um referencial teórico sobre ouvidoria pública no Brasil e no SUS; a segunda discute as categorias teóricas usada para entender o papel das ouvidorias públicas na sociedade democrática; a terceira seção descreve as características e a organização estrutural da Ouvidoria-Geral do SUS; a quarta apresenta os aspectos metodológicos da pesquisa; a quinta parte descreve os resultados da pesquisa a partir dos relatórios gerenciais da Ouvidoria-Geral do SUS e da discussão dos mesmos e, por fim, apresentamos algumas conclusôes sobre o estudo.

\section{Reflexões sobre a Ouvidoria Pública no Brasil e no SUS}

Ouvir é um sentido e uma das ações humanas mais básicas e elementares na comunicação. Essa ação é bastante relevante quando se trata de responsividade e accountability no âmbito da gestáo pública (FERNANDES; MOREIRA; RIBEIRO, 2016). Nesse sentido, a criação de ouvidorias representa um avanço significativo para a administração pública brasileira no campo da gestão democrática.

$\mathrm{Na}$ discussão sobre modelo ideal de ouvidoria pública, a transparência, a autonomia e a promoção da participaçáo e do controle social são centrais. Assim, 
para que as ouvidorias públicas cumpram seu papel no fortalecimento da democracia participativa e no aperfeiçoamento da gestão pública, é fundamental que os ouvidores exerçam suas atribuiçôes com autonomia e independência (MENEZES; NETO; CARDOSO, 2016).

O desenvolvimento das estruturas burocráticas do Estado gerou a necessidade de proteção de direitos dos cidadãos contra usos e abusos do poder público. A inexistência de controle efetivo e penalidades aplicáveis ao serviço público enfraquece o ideal democrático limitando a influência dos cidadãos no funcionamento das instituições do Estado e os expondo aos riscos potenciais da burocracia. Portanto, a autonomia das ouvidorias públicas está relacionada ao provimento de estruturas que possibilitem o accountability societal, com o objetivo de expor os erros governamentais e ativar o funcionamento das agências horizontais (MENEZES; NETO; CARDOSO, 2016).

Dessa forma, o papel da ouvidoria não é se contrapor ao órgão/entidade na defesa do cidadão, mas garantir que a demanda da cidadania seja considerada e tratada, à luz das garantias constitucionais e legais, atuando no sentido de recomendar adequações necessárias ao efetivo funcionamento da administração pública (SILVA; PEDROZO; ZUCCHI, 2014).

Na saúde, apesar da Ouvidoria do SUS existir em todos os estados, para que se configure realmente um sistema nacional de ouvidorias urge a dinamização da implantação dessas instâncias a nível municipal. Também é estratégica a utilização de tecnologias de informática visando a expansão da capacidade comunicativa com a Ouvidoria do SUS/Ministério da Saúde e com os usuários. Além disso, é fundamental atentar para as diferenças e assimetrias locorregionais entre municípios, regiōes e estados, no âmbito social, político, cultural, econômico e, mais especificamente, na área da saúde (FERNANDES; MOREIRA; RIBEIRO, 2016).

As atividades realizadas pelas Ouvidorias do SUS têm possibilitado ampliação das reflexôes sobre as políticas de saúde, contribuindo para seu aprimoramento e capacidade de gestáo e envolvimento da população (NETO; DÚRAN, 2016; FERNANDES; MOREIRA; RIBEIRO, 2016). A despeito dos avanços alcançados com a implantação das Ouvidorias, há ainda um considerável distanciamento entre o seu propósito ideal e suas atuais condiçóes concretas (NETO; DÚRAN, 2016). O presente artigo realizará uma análise sobre a atuação da Ouvidoria do SUS levando em consideração seus avanços e pendências. 


\section{Categorias teóricas para a análise: os diferentes papéis das ouvidorias em uma sociedade democrática}

A democracia deve ir além de um método para escolher quem governa. Percebese que ela está vinculada à busca histórica de liberdade, justiça e progresso material e pessoal (PNUD, 2004). Portanto, a participação direta da cidadania na política vem sendo considerada um termômetro da qualidade da democracia ao longo do tempo.

Com o regresso do Brasil às vias institucionais democráticas, depois de um longo período de regime militar, o país reestruturou a sua ordem política. A nova Constituição Federal de 1988 adotou o princípio da participação popular na elaboração e formulação das políticas de saúde, assistência social, educação e direitos da criança e do adolescente, entre outras. A participação popular passou a estar presente em vários dispositivos do texto constitucional (FERNANDEZ et al., 2019). Em um cenário de transição e reformas estruturais aparecem os desafios para a regulamentação e institucionalização dos dispositivos constitucionais democratizantes, diante das dificuldades de pactuação evidenciadas no cenário político brasileiro.

É nesse contexto profundamente complexo que surgem as ouvidorias públicas, com o objetivo de permitir a escuta direta da população. Apesar das ouvidorias não aparecerem expressamente na Constituição, também são produto do protagonismo da sociedade civil, cujos desejos por participação vem modelando uma nova forma de relacionamento entre o Estado e os usuários dos serviços públicos (LYRA, 2008). Como resultado desse debate político, são implementadas ouvidorias por todo o país. Lideradas pelas prefeituras e estados federados, essas ouvidorias inauguram os primeiros canais de comunicação com o cidadão usuário dos serviços descentralizados (FERNANDEZ et al., 2019).

As ouvidorias públicas são capazes de transportar o cidadão para o centro da administração pública, dão voz ativa ao indivíduo, permitindo que suas críticas, sugestões e/ou denúncias possam contribuir para correção e aprimoramento das políticas públicas. As ouvidorias permitem que os cidadáos participem. Portanto, a participação é a primeira categoria analítica utilizada aqui para observar o papel das ouvidorias.

A participação da cidadania é ferramenta central da democracia participativa. $\mathrm{O}$ espaço da democracia participativa é aquele em que o cidadão tem protagonismo junto ao governo nas ações públicas e na gestão das políticas públicas. Logo, por 
meio da ouvidoria, o cidadão participa da gestão de políticas, na medida em que as sugestōes, críticas e observações dos usuários são acatadas pela instituição em questão (LYRA, 2001). Assim, um dos papeis das ouvidorias é estabelecer-se como canal de participação cidadá na gestão das políticas.

Um segundo papel que pode ser desempenhado por meio das ouvidorias é a possibilidade de execuçáo do controle social pela cidadania. $O$ controle social deriva diretamente da participação cidadã. Através do ato de participar, o usuário cria a capacidade de controlar a gestão das políticas. As ouvidorias possibilitam ao usuário fiscalizar as prestaçôes de serviços e atendimento de instituiçôes públicas; acessar registros e informaçóes sobre atos de governo; bem como realizar denúncias em casos de não responsabilização dos gestores públicos quanto ao cumprimento das suas atribuiçôes básicas (ANTUNES et al., 2007).

No contexto da atual gestão pública, as ouvidorias destacam-se como canais de comunicação entre o cidadão e a administração e como ferramenta de controle, para a concretização da prestação de contas democrática (SERRA et al., 2012). Assim, as ouvidorias possibilitam o controle social, garantindo a responsabilização da gestão pública e favorecendo o incremento da transparência no serviço público (BRESSER-PEREIRA, 1999).

Por fim, a terceira função das ouvidorias destaca a possibilidade de servir como instrumento de avaliação de políticas públicas. Avaliar políticas passa por avaliar a satisfação dos usuários com as políticas implementadas. Observa-se, frequentemente, nas práticas avaliativas a não centralidade no usuário a partir do que ele pensa e vive, mas a partir de como esse serviço o vê. $\mathrm{O}$ reconhecimento das potencialidades e a oferta de mecanismos que possibilitem melhorar a gestão da saúde apresentamse como estratégias factíveis e robustas, que ganham contornos especiais quando contemplam práticas avaliativas na perspectiva de usuários (PINTO et al., 2015).

A satisfação do usuário é considerada uma meta a ser alcançada pelos serviços, devendo, portanto, ser pesquisada visando o aperfeiçoamento dos serviços de saúde (ESPERIDIÃO; TRAD, 2006). Neste sentido, as ouvidorias possuem um papel importante para a avaliação de políticas considerando que têm a capacidade de coletar e disponibilizar dados e informaçôes sobre a satisfação dos usuários de serviços públicos.

A ouvidoria se constituiu, com o passar do tempo, em um espaço para a melhoria dos serviços prestados, favorecendo a avaliação e o aprimoramento das atividades de organização das políticas. Por meio do acompanhamento do fluxo das solicitaçóes 
apresentadas pelos usuários como busca de solução de problemas e pela análise das informações obtidas é possível identificar as áreas que necessitam maior atenção, embasando a definição de novos planos de ação (ALVES JUNIOR, 2002).

O processo de democratização passa pela aproximação das políticas públicas aos cidadãos, pelo alcance das decisôes políticas a esta cidadania e pela possibilidade do controle democrático mediante práticas participativas. No cenário políticoadministrativo brasileiro, reconhece-se as necessidades de participação, controle, regulação, análise e avaliação de políticas públicas. Admite-se também a importância do aperfeiçoamento e da inovação constantes na gestão das políticas públicas na área da saúde. As ouvidorias públicas são instrumentos importantes para o alcance desses objetivos.

\section{A ouvidoria-geral do SUS: história, estrutura e funcionamento}

O cenário de redemocratização serviu de terreno fértil para práticas participativas. Em 1985, surgiu na empresa Rhodia a primeira ouvidoria privada. Em 1986, surgiu a Ouvidoria Municipal de Curitiba, a primeira ouvidoria pública, tornando o Paraná o primeiro estado brasileiro a instituir uma ouvidoria estadual.

De forma rápida as ouvidorias começaram a ser implantadas no país e, em 2003, mediante o Decreto no 4.726, foi criado o Departamento de Ouvidoria-Geral do SUS (Doges) ligado à Secretaria de Gestão Estratégica e Participativa (SGEP) do Ministério da Saúde (MS). Com isso, configurou-se uma rede interligada de ouvidorias, implantadas na Uniáo, nos estados e nos municípios, que funcionam de forma descentralizada, sob orientação estratégica central do Doges/MS. Em 2019, com a mudança na estrutura do MS instituída pelo Decreto no 9.795 , extinguiu a SGEP e seus departamentos foram realocados. Desde então, a Ouvidoria-Geral do SUS passou a ser vinculada à Diretoria de Integridade (DINTEG), uma nova diretoria com subordinação direta ao Gabinete do Ministro.

A Ouvidoria-Geral do SUS passou a ter maior abrangência e relevância no país a partir de 1996, frente à pandemia da AIDS quando foram necessárias estratégias para adquirir dados e repassar informaçôes sobre a doença e de outras sexualmente transmissíveis. Criou-se o "Pergunte AIDS", que o seu uso por parte da população permitiu a construção de um banco de dados com elementos importantes para o entendimento da doença. 
O êxito do "Pergunte AIDS” culminou na ampliação da estratégia, transformandose em 1997 em Disque Saúde. Com isso, as informaçóes repassadas passaram a englobar outras patologias, como outras doenças infecciosas, doenças cardíacas e outros agravos, açôes e políticas de saúde, informaçôes sobre os Conselhos de Saúde, transplantes de órgãos, entre outros assuntos de utilidade pública. Essas atividades iniciais renderam ao Doges experiências positivas, tanto que diversas parcerias foram firmadas como o Disque Pare de Fumar, Disque Saúde da Mulher, Disque Denúncia de Abuso e Exploração Sexual Contra Crianças e Adolescentes (DDAES), Disque Medicamentos, Central de Atendimento à Mulher (CAM).

Em 2006 ocorreu a unificaçáo dos serviços, exceto o Disque DDAES e CAM. Assim, todos os assuntos incorporaram o elenco de informaçóes prestadas pelo Disque Saúde, otimizando o atendimento ao cidadão, passando a ter que memorizar um único número telefônico de referência nacional, facilitando o contato e reduzindo custos da ligação.

Em 2008 discutiu-se a viabilidade do Disque Saúde - 0800611997 - se tornar um tridígito. O objetivo era caracterizá-lo como um serviço de utilidade pública, além de facilitar a memorização e ampliação do canal de escuta, seria possível evitar o acréscimo de diferentes números telefônicos de Discagem Direta Gratuita. Então, em 2011, o Disque Saúde adotou o número 136.

Atualmente, a concepção do Disque Saúde foi ampliada. A princípio realizavase apenas a modalidade de atendimento ativo, no qual o cidadão busca o serviço, porém, já é possível a realização do atendimento passivo. Nessa modalidade a lógica se inverte, o contato com usuário parte da Ouvidoria-Geral do SUS por meio do Disque Saúde.

Disque Saúde se transformou no canal de entrada mais conhecido por ter caráter informativo, além de contar com uma ampla divulgação em cartazes e publicaçóes do MS, em maços de cigarro e extratos bancários. Portanto, a Ouvidoria do SUS foi concebida, diferentemente de outras, disseminando informaçóes em saúde, consequentemente agindo em primeiro nível de atendimento.

\section{Ouvidoria-Geral do SUS: estrutura e funcionamento}

A Ouvidoria-Geral do SUS busca ampliar o acesso dos usuários ao processo de avaliação das açóes e serviços públicos de saúde. Desempenha os papeis de espaço 
de cidadania, mediação no acesso a serviços de saúde e instrumento de gestão. Uma de suas competências atuais é viabilizar e coordenar a realização de estudos e pesquisas visando a produção do conhecimento para subsidiar a formulação de políticas de gestão do SUS.

Para o cumprimento desta competência, a Ouvidoria instituiu em 2011 o Núcleo de Pesquisa (Nupe), que tem como atribuição a realização das pesquisas solicitadas pelo Gabinete do Ministro de Estado da Saúde, pelas Secretarias do MS e ainda aquelas fomentadas pela própria Ouvidoria, em parceria ou não com outros órgãos.

As ouvidorias do SUS devem ser descentralizadas, de forma a serem implantadas e operacionalizadas também pelos estados e pelos municípios, para que o conjunto de açôes e serviços de saúde possa ser avaliado pela população. Destaca-se que essas ouvidorias não são apenas caracterizadas por receberem reclamaçôes dos usuários, sua concepção vai além, devendo ser capazes de acolher demandas referentes a informações, sugestôes, solicitaçôes, denúncias e elogios.

Segundo o Decreto no 6.860, de 27 de maio de 2009 as competências do Doges/ MS são:

I. Propor, coordenar e implementar a Política Nacional de Ouvidoria em Saúde, no âmbito do SUS;

II. Estimular e apoiar a criação de estruturas descentralizadas de Ouvidoria em Saúde;

III. Implementar políticas de estímulo à participação de usuários e entidades da sociedade no processo de avaliação dos serviços prestados pelo SUS;

IV. Promover açôes para assegurar a preservação dos aspectos éticos, de privacidade e confidencialidade em todas as etapas do processamento das informações decorrentes;

V. Assegurar aos cidadãos o acesso às informações sobre o direito à saúde e às relativas ao exercício desse direito;

VI. Acionar os órgãos competentes para a correção de problemas identificados, mediante reclamaçóes enviadas diretamente ao MS, contra atos ilegais ou indevidos e omissóes no âmbito da saúde; e

VII. Viabilizar e coordenar a realização de estudos e pesquisas visando à produção do conhecimento, no campo da Ouvidoria em saúde, para subsidiar a formulação de políticas de gestão do SUS. 
A Ouvidoria-Geral do SUS disponibiliza vários canais de entrada para que o cidadão se manifeste, buscando facilitar o acesso. O primeiro canal de entrada é a carta. As cartas dos cidadãos recebidas são direcionadas aos mais diversos órgãos do governo federal. Outro canal de entrada é o atendimento presencial, no qual o cidadão se dirige até a Ouvidoria para dialogar sobre suas manifestações. Um terceiro canal é o telefone, o Disque Saúde (BRASIL, 2014a). Hoje há também o FormulárioWEB, que pode ser acessado pelo site do MS. A ampliação dos canais de entrada é uma estratégia de inovar no atendimento e agilizar os registros das mensagens recebidas (BRASIL, 2014a).

Diante do exposto, a Ouvidoria transita entre o papel de representação do cidadão e de representação do SUS, atuando muitas vezes como mediador de conflitos. Entretanto, sua ação visa provocar mudanças, promover benefícios comuns, coletivos, considerando também a questão pessoal contida na demanda.

\section{Aspectos metodológicos}

Para cumprir com o objetivo do artigo, ou seja, analisar a Ouvidoria-Geral do SUS a partir das vias de atuação das ouvidorias públicas, de acordo com a bibliografia especializada, foi formulada a seguinte pergunta de pesquisa: como a Ouvidoria-Geral do SUS atua no âmbito das políticas de saúde? Para responder tal questão, realizou-se pesquisa e análise documental a partir dos relatórios gerenciais do Doges/MS produzidos entre 2010 e 2017.

A pesquisa documental constitui uma técnica qualitativa importante, seja para complementar informaçóes obtidas por outras técnicas, seja para apresentar conteúdos novos sobre um determinado tema (LÜDKE; ANDRÉ, 1986). Esse tipo de pesquisa analisa fontes primárias, utilizando-se de materiais que ainda não receberam tratamento analítico ou que podem ser reelaborados de acordo com os objetivos da pesquisa (GIL, 2008).

O objetivo é identificar nos documentos informaçóes que sirvam de subsídio para responder à questão de pesquisa. Os relatórios gerenciais serviram como fontes primárias submetidas à análise, pois possuem um conjunto de informaçôes que tem como objetivo apresentar a situação geral de uma organização de forma transparente e direta. Esses relatórios são fundamentais para que o gestor possa identificar carências e corrigir percursos das políticas, já que relatam as demandas da população e atividades da instituição. 
A análise de dados qualitativos é um processo que exige rigor intelectual, sistematização e coerência do esquema escolhido com o que se pretende analisar (PATTON, 1980). Nesse sentido, a etapa de análise dos documentos propóe-se a produzir ou reelaborar conhecimentos e criar formas de compreender os fenômenos. A partir daí o pesquisador deve interpretar os achados, sintetizar as informaçóes, determinar tendências e, quando possível, fazer inferências (SÁ-SILVA et al., 2009).

Quando um pesquisador decide por utilizar documentos para retirar dele informações, ele o faz investigando, examinando, usando técnicas apropriadas para seu manuseio e análise; seguindo etapas e procedimentos; organizando informaçóes a serem categorizadas e posteriormente analisadas e elaborando sínteses (SÁ-SILVA et al., 2009). Assim, estudos baseados em documentos como material primordial extraem deles toda a análise, organizando-os e interpretando-os segundo os objetivos da investigação proposta (PIMENTEL, 2001).

Buscou-se construir uma matriz categórica de análise a partir das categorias de atuação apresentadas pela literatura. Foi realizada uma descrição analítica, com base no referencial teórico e na análise dos documentos para organizar os dados em categorias. Esse esforço por detectar padrōes, temas e categorias é um processo criativo que requer observações e decisóes cuidadosas sobre o que realmente é relevante e significativo nos dados (PATTON, 1980) e que, ao mesmo tempo, se conecta com as categorias apontadas por estudos anteriores. Ademais, o pesquisador deve estar atento a novas categorias relevantes que, por ventura, surjam no material analisado.

A matriz categórica utilizada na presente pesquisa divide-se em três temas conforme Quadro 1, que apresenta cada uma das categorias e a forma como elas foram "medidas" a partir das informaçôes contidas nos relatórios de gestão do Doges.

\section{Quadiro 1. Categorias que compóem a matriz de análise.}

\begin{tabular}{|l|l|}
\hline Categoria & Medida \\
\hline Participação da cidadania & Acesso da população aos diferentes canais da ouvidoria. \\
\hline Controle social & Açóes e canais existentes entre ouvidoria e população. \\
\hline $\begin{array}{l}\text { Avaliação de política } \\
\text { de saúde }\end{array}$ & $\begin{array}{l}\text { Manifestaçóes protocoladas pelos usuários, avaliação geral do usuário } \\
\text { ou do próprio MS sobre a política ou a ouvidoria. }\end{array}$ \\
\hline
\end{tabular}

Fonte: Elaboração própria. 


\section{Mapeando as atividades da Ouvidoria-Geral do SUS}

É sabido que as ouvidorias públicas exercem um importante papel de diálogo entre Estado e cidadáos. Dessa mesma forma, atua a Ouvidoria-Geral do SUS, vinculando o sistema de saúde e os usuários. A seguir, serão apresentadas as atividades da Ouvidoria-Geral do SUS em três frentes: participação da cidadania, controle social e avaliação de políticas de saúde.

\section{Participaçáo da cidadania}

Após a redemocratização, uma das principais questóes enfrentada pelo Estado brasileiro tem sido harmonizar as crescentes demandas sociais com um desenho institucional voltado à participação. A ideia de gestão pública eficaz pressupôe a garantia dos direitos fundamentais constitucionalmente assegurados, a presença concreta do caráter democrático traduzido no desenho institucional da gestão e o permanente diálogo entre ambiente público e a sociedade (SERRA et al., 2012). Nessa perspectiva também atua a Ouvidoria-Geral do SUS.

Como mostra o Gráfico 1, o número de manifestaçóes dos usuários vem crescendo entre 2010 e 2017. Chama a atenção o pico de atividade de participação dos usuários via Ouvidoria no ano de 2013, com a maior quantidade de interaçôes da série histórica, 56.164 mil. Excluindo esse ano atípico, percebemos uma crescente constante dentro do período observado.

Gráfico 1. Manifestaçôes protocoladas na Ouvidoria-Geral do SUS entre 2010 e 2017.

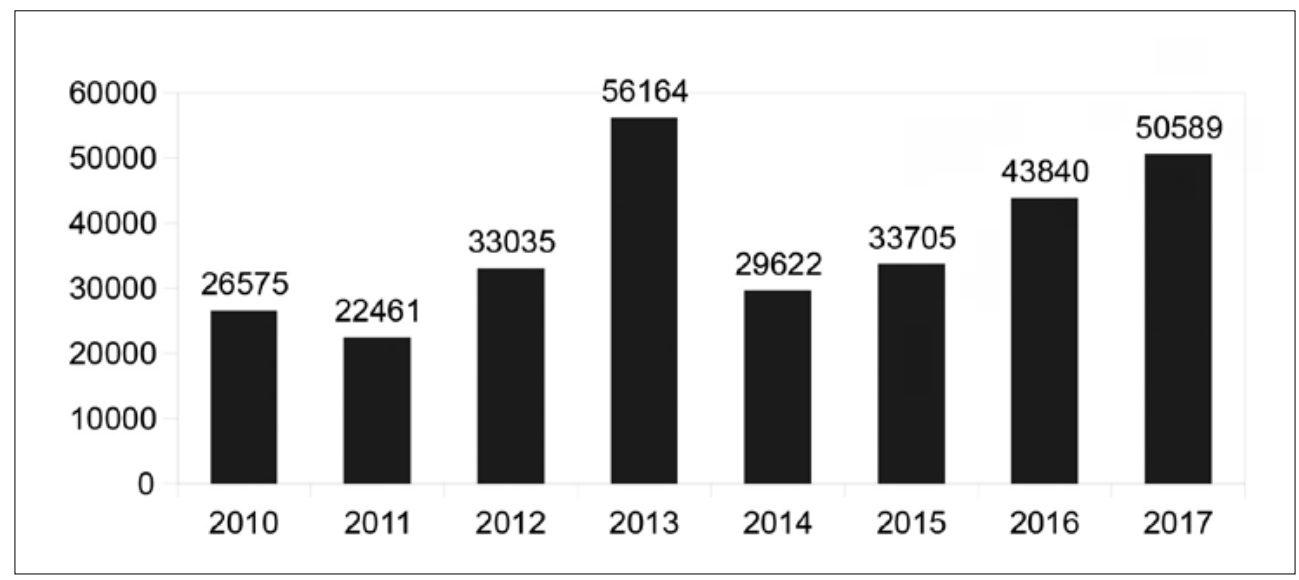

Fonte: Elaboração própria com base nos dados do Doges/MS. 
Quando classificamos as manifestaçôes por tipo, conforme a Tabela 1, na grande maioria dos anos observados, com exceçáo de 2012, as "solicitaçóes" são o tipo de manifestação mais utilizado pelos usuários. As "denúncias" e as "reclamaçôes" também estão entre as manifestações mais acessadas. Os "elogios" e as "sugestôes" são os tipos de interação menos presente em todos os anos da série temporal observada.

Tabela 1. Manifestaçóes protocoladas na Ouvidoria-Geral do SUS por ano e por tipo.

\begin{tabular}{|c|c|c|c|c|c|c|c|}
\hline \multirow{2}{*}{ Ano } & \multirow{2}{*}{$\begin{array}{c}\text { Manifestaçóes } \\
\text { Protocoladas }\end{array}$} & \multicolumn{5}{|c|}{ Classificaçáo das Manifestaçóes Protocoladas } \\
\cline { 3 - 8 } & Informaçóes & Solicitaçóes & Denúncias & Reclamaçóes & Sugestóes & Elogios \\
\hline 2010 & 26.575 & $18,0 \%$ & $34,7 \%$ & $22,8 \%$ & $20,8 \%$ & $2,8 \%$ & $0,9 \%$ \\
\hline 2011 & 22.461 & $11,6 \%$ & $30,1 \%$ & $22,7 \%$ & $30,7 \%$ & $3,5 \%$ & $1,4 \%$ \\
\hline 2012 & 33.035 & $4,8 \%$ & $30,1 \%$ & $32,7 \%$ & $28,2 \%$ & $2,0 \%$ & $2,2 \%$ \\
\hline 2013 & 56.164 & - & $34,5 \%$ & $24,6 \%$ & $31,2 \%$ & - & - \\
\hline 2014 & 29.622 & $3,7 \%$ & $39,0 \%$ & $26,8 \%$ & $26,2 \%$ & $2,5 \%$ & $1,8 \%$ \\
\hline 2015 & 33.705 & $6,0 \%$ & $34,3 \%$ & $31,0 \%$ & $23,0 \%$ & $3,2 \%$ & $2,5 \%$ \\
\hline 2016 & 43.840 & $7,3 \%$ & $38,2 \%$ & $21,7 \%$ & $28,1 \%$ & $2,6 \%$ & $2,1 \%$ \\
\hline 2017 & 50.589 & $7,6 \%$ & $37,3 \%$ & $23,1 \%$ & $28,4 \%$ & $1,8 \%$ & $1,8 \%$ \\
\hline
\end{tabular}

Nota: No Relatório de 2013 contém apenas o percentual agregado para as classificaçóes "Informaçóes”, "Sugestóes" e "Elogios", que corresponde a 9,7\% do total das manifestaçóes protocoladas em 2013. Por isso, não foi possível apresentar na tabela os valores individuais para cada tipo de manifestação nesse ano. Fonte: Elaboração própria com base nos dados do Doges/MS.

Diversos canais de entrada de manifestações são disponibilizados para permitir a participação dos usuários junto à Ouvidoria. O Disque Saúde foi bastante utilizado pelos usuários no período observado, com pico de participação em 2013. Não foram apresentados dados do Disque Saúde nos relatórios de 2015, 2016 e 2017 (ver tabela 2). Nos relatórios de 2010 a 2012 verificou-se que a região Sudeste originou a maioria das chamadas via Atendimento Telefônico e a menor participação foi da região Norte do país.

Com relação ao Atendimento Eletrônico na URA (ferramenta deacessoàsinformações previamente gravadas que permitem o esclarecimento de dúvidas sobre determinados assuntos sem necessidade de falar com o teleatendente), o ano de 2012 apresentou maior participação de usuário. Percebe-se ainda que ao longo do tempo analisado houve uma clara diminuição do número desses atendimentos, conforme tabela 2. 
O Atendimento Humano é outro meio para acesso do usuário à Ouvidoria-Geral do SUS. Ao contrário do ocorrido com o Atendimento Eletrônico, no Atendimento Humano pode se dizer, de forma geral, que houve um aumento do uso deste canal de interação e participação. $\mathrm{O}$ ano de 2015 se destacou em relação às informaçôes prestadas a partir desse tipo de atendimento.

Tabela 2. Manifestaçôes recebidas na Ouvidoria-Geral do SUS por tipo de canal e ano.

\begin{tabular}{|c|c|c|c|}
\hline \multirow{2}{*}{ Ano } & \multicolumn{3}{|c|}{ Canal } \\
\cline { 2 - 4 } & Disque Saúde & Atendimento Eletrônico & Atendimento Humano \\
\hline $\mathbf{2 0 1 0}$ & $4.556,588$ & $8.528,027$ & 265.692 \\
\hline $\mathbf{2 0 1 1}$ & $3.580,846$ & $6.419,913$ & 147.140 \\
\hline $\mathbf{2 0 1 2}$ & $4.126,891$ & $8.847,187$ & 311.567 \\
\hline $\mathbf{2 0 1 3}$ & $4.672,290$ & $4.325,954$ & 351.734 \\
\hline $\mathbf{2 0 1 4}$ & $3.954,334$ & $6.090,943$ & 423.038 \\
\hline $\mathbf{2 0 1 5}$ & - & $1.324,84$ & 608.471 \\
\hline $\mathbf{2 0 1 6}$ & - & $2.004,484$ & 510.705 \\
\hline $\mathbf{2 0 1 7}$ & - & 807,429 & 436.574 \\
\hline
\end{tabular}

Fonte: Elaboração própria com base nos dados do Doges/MS.

Ainda sobre o Atendimento Humano, foi possível identificar os temas tratados nesse contato. Em 2010, os temas de destaque foram: Orientado a procurar serviço de saúde, Tabagismo, Gripe comum e Influenza A (H1N1), Programa Farmácia Popular e AIDS. Em 2011, destacaram-se: Programa Farmácia Popular do Brasil (PFPB), Tabagismo e Aids. Já em 2012, os principais temas foram: Informaçóes sobre o SUS, Programa Farmácia Popular do Brasil, Saúde da Mulher e Tabagismo. Em 2013, os temas mais acessados foram: Tabagismo; Programa Brasil Sorridente; Programa Farmácia Popular do Brasil; e DST. No ano de 2014 os principais temas foram: Tabagismo; Programa Farmácia Popular do Brasil; DST; e especificamente sobre AIDS. A partir de 2015, somente estão registradas a informação sobre a quantidade de atendimentos, sem detalhamento dos temas.

Observou-se que os temas tratados variam de acordo com as políticas existentes ou diante daquelas que surgem em determinado momento. Significa que a busca do usuário também é pautada pelo que chega até ele nos serviços de saúde ou pelos 
meios de informação e comunicação. Um exemplo é o Programa Farmácia Popular do Brasil, que foi o tema mais recorrente devido ao lançamento do programa "Saúde Não Tem Preço” em 2011. Há ainda temas que persistem ao longo do tempo, como o Tabagismo e as Doenças Sexualmente Transmissíveis e AIDS.

Em 2013 foi criada a Ouvidoria Itinerante (OI), considerada uma ação de ouvidoria ativa que ocorria com o deslocamento de profissionais do Doges para áreas de difícil acesso aos serviços de saúde, visando alcançar populaçóes que vivem em condiçôes de vulnerabilidade social e sem acesso a Ouvidora-Geral do SUS. Esse canal possibilitou a participação de usuários que, a priori, estariam marginados desse processo.

A OI utilizou metodologia horizontal de sensibilização e de conscientização das populações vulneráveis, mediante o empoderamento e da educação popular. As ações foram realizadas em parceria com a Organização Pan-Americana de Saúde, com outros departamentos do MS, com os movimentos sociais e com instituiçôes de ensino superior. Em 2013, foram desenvolvidos cinco projetos em parcerias com a Federação dos Trabalhadores na Agricultura do Rio Grande do Sul, Caravanas das Ouvidorias, Centro Nordestino de Medicina Popular, União Brasileira de Mulheres e Rádio Web Saúde/UnB.

Em 2014, durante a Copa do Mundo de Futebol ocorrida no Brasil, o Disque Saúde 136 ofertou atendimento específico em virtude do evento. Foi operacionalizado o serviço também em línguas inglesa e espanhola para atender às manifestaçóes. Foram realizados 43.302 atendimentos, sendo a maior parte em espanhol (cerca de $50 \%$ ), seguido de português e inglês, com cerca de $25 \%$ cada.

Um questionário específico buscou coletar o perfil dos usuários estrangeiros que acessaram a Ouvidoria-Geral do SUS durante a Copa. Observou-se que a maioria era dos Estados Unidos (16\%) e a maior parte dos estrangeiros estavam hospedados no Distrito Federal (mais de 20\%). Foram disseminadas 198 informações e 4 manifestaçóes foram protocoladas. Sobre as informaçóes, o tema mais propagado se referia a orientaçôes gerais: vacinas e prevenção contra febre amarela e malária. As manifestaçôes registradas estavam relacionadas à gestáo ou à vigilância sanitária, sendo 3 denúncias e 1 reclamação.

Cabe ressaltar que, para toda manifestação recebida, a Ouvidoria não realiza apenas encaminhamento ao órgão responsável. O objetivo é apresentar ao cidadão as políticas públicas disponíveis, além de buscar esclarecer a forma de acessá-las. 


\section{Controle social}

Entre os usuários do SUS uma das formas de buscar seus direitos é recorrendo à ouvidoria e aos demais instrumentos que possibilitam controle social, como os conselhos e conferências de saúde. Essa interação permite a avaliaçáo de condutas do sistema de saúde, a melhoria dos serviços prestados e a fiscalizaçáo dos recursos públicos (ANTUNES, 2008). O controle social das políticas públicas é uma ferramenta democrática importante nas sociedades atuais. A Ouvidoria-Geral do SUS possibilita aos usuários exercer atividades de controle sobre as políticas públicas de saúde.

Um aspecto fundamental, que diferencia as Ouvidorias do SUS das demais ouvidorias clássicas, é seu caráter de disseminar informaçôes a partir de um banco próprio, cujo conteúdo é elaborado e atualizado conjuntamente às áreas técnicas do MS. Essa ação constitui um aspecto fundamental no entendimento de que as Ouvidorias possuem postura proativa à medida que fornecem orientaçóes sobre saúde à população.

A Ouvidoria-Geral do SUS possui um banco de dados em saúde, a partir do qual disseminam diversas informaçóes, visando estimular o diálogo com a populaçáo sobre diferentes temas. As linhas gerais das categorias de informações tratadas são: gestão do SUS; doenças e orientaçôes em saúde; rede do SUS; campanhas e ações estratégicas e/ou emergenciais. Quando o usuário tem a possibilidade de obter informações precisas sobre diferentes políticas, ele pode capacitar-se para exercer atividades de controle sobre as mesmas.

Outro canal disponível na Ouvidoria-Geral do SUS é a Carta SUS, com implantação em 2012 e suspensa em 2016. A carta era enviada a todos os usuários do SUS que realizaram internaçóes hospitalares (AIH) ou procedimento ambulatorial de alta custo/complexidade (APAC). Os objetivos da estratégia Carta são: fiscalização, transparência e avaliação, a evidência como mais um mecanismo controle social disponível para o usuário. A estratégia é uma prática de ouvidoria ativa, na qual o MS, por meio do Doges, envia cartas-pesquisa para os usuários que passaram por internação ou procedimento de alta complexidade e espera respostas com informaçóes.

Com a Carta SUS foi registrado um número significativo de denúncias, versando basicamente sobre: faturamento, dados divergentes e cobrança indevida. $\mathrm{O}$ número 
de cartas geradas em 2012 foi de 10.081.233. Em 2013, foram enviadas 13.638.196 cartas para usuários, porém, destas, 3.945.644 foram devolvidas pelos correios por diversos motivos (endereço insuficiente ou inexistente). Em 2014 foram enviadas 13.806,708 cartas para usuários, com devolução de 2.799.300 pelos correios. Em 2015 foram enviadas 12.339.487 cartas e devolvidas 3.622.616. Em 2016 foram enviadas 4.964.107 cartas para usuários, dessas 1.086.962 devolvidas.

A partir da quantidade de cartas enviadas e devolvidas passou-se a calcular a "Taxa de alcance" das cartas expedidas, que representa o percentual de usuários que receberam a correspondência. Em 2015, a taxa de alcance foi de aproximadamente $71 \%$ (a cada dez usuários, sete receberam a correspondência). Com a Carta foi extinta não houve mais cálculo da taxa.

Face aos objetivos da Carta SUS, entende-se que ela cumpre o seu papel nas questôes inerentes ao acesso à informação, principalmente nos princípios: Máxima Divulgação (o direito de acesso deve abranger o maior tipo de informaçóes e órgãos possíveis e deve alcançar o maior número de indivíduos) e Obrigação de Publicar (os órgãos públicos têm a obrigação de publicar informaçôes de grande interesse público). Na cultura de acesso, o fluxo de informaçôes favorece o controle social, a tomada de decisões, a boa gestão de políticas públicas e a inclusão do cidadão.

A análise mostra que os cartóes-resposta da Carta SUS retornavam com maior frequência no ano posterior à emissão. Isto significa que, caso a estratégia não tivesse sido suspensa, a cada ano poderia apresentar, de acordo com a tendência, maior quantitativo de respostas referentes às cartas emitidas.

Como vimos na seção sobre participação da cidadania, diferentes mecanismos visam garantir a participaçáo dos usuários do SUS. Entre as categorias de manifestaçóes, a que mais colabora para o controle social via Ouvidoria-Geral do SUS é a "denúncia". A partir de 2013, coincidindo com o surgimento da Carta SUS, observamos alguns picos de denúncias na série temporal (ver Gráfico 2). Com as correspondências enviadas pelo MS, os cidadãos-usuários puderam conferir os procedimentos realizados, valores pagos e outros dados referentes ao seu atendimento. Assim, a estratégia cumpre com seus objetivos de fiscalização dos serviços, possibilitando o controle dos recursos públicos e aferição da qualidade do atendimento oferecido. Reforçou ainda mais o controle e a participação da população na gestão do SUS. 
Gráfico 2. Percentual de manifestaçôes protocoladas como "denúncia” por ano.

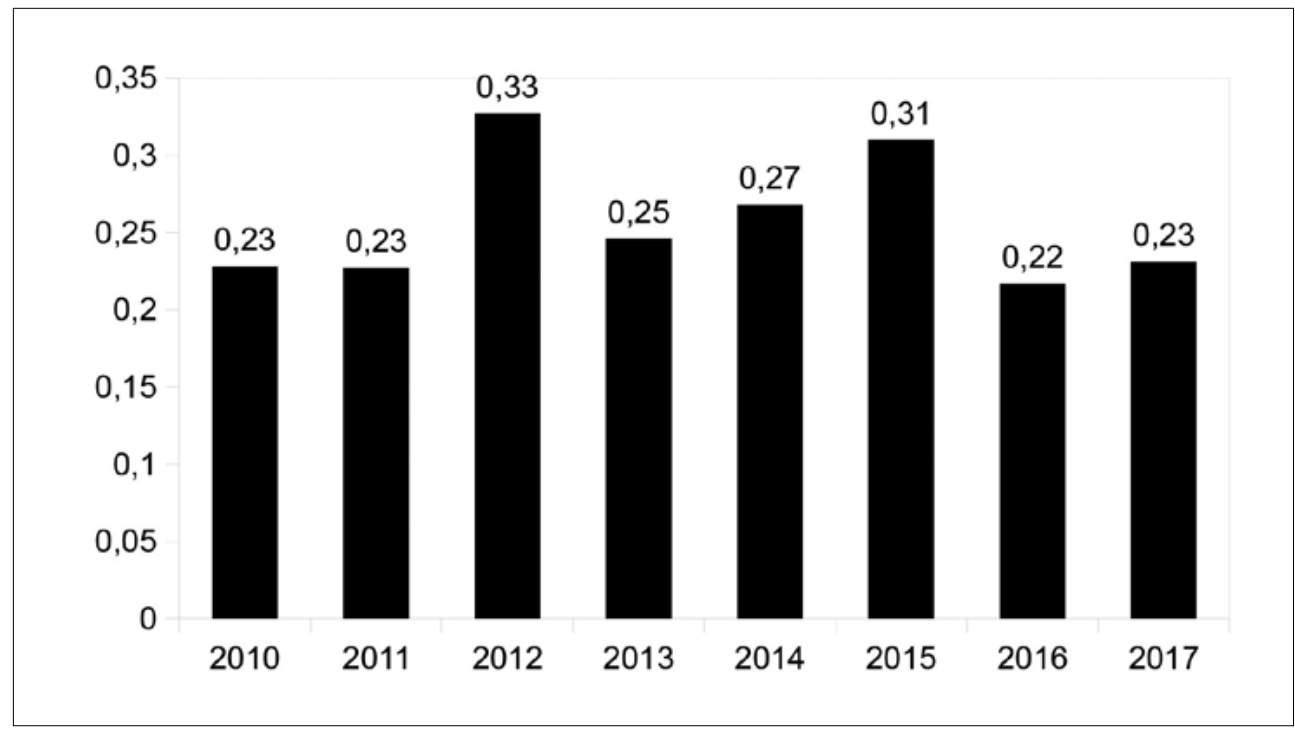

Fonte: Elaboraçáo própria com base nos dados do Doges/MS.

Em 2012, entrou em vigor a Lei no 12.527, ou Lei de Acesso a Informação (LAI), com o propósito regulamentar o direito constitucional de acesso dos cidadãos às informações públicas e seus dispositivos são aplicáveis a todos os entes federados. Tal publicação significou um importante passo na direção da transparência pública e controle popular, já que permite uma maior participação popular e o controle social das açóes governamentais, o acesso da sociedade às informaçóes públicas permite que ocorra melhoria na gestáo pública.

A Lei determina que os órgãos públicos criem o Serviço de Informação ao Cidadão (SIC), devendo se estruturar para atender e orientar o público quanto ao acesso a informações de interesse coletivo, como: tramitação de documentos, processos de licitaçôes e gastos públicos. Estabelece ainda que as entidades públicas divulguem na internet, em linguagem clara e de fácil acesso, dados sobre a administração pública. No mesmo ano, o SIC foi criado com o objetivo de: atender e orientar o público quanto ao acesso à informação; informar sobre a tramitaçáo de documentos nas unidades do MS; receber e registrar pedidos de acesso à informação. Neste ano, foram registrados no MS 1.183 pedidos no âmbito da LAI. 


\section{Avaliação de políticas de saúde}

A partir das manifestaçóes recebidas pela Ouvidoria-Geral do SUS, é possível observar a percepção e satisfação da população quanto ao acesso e qualidade do sistema de saúde. A medida da satisfação dos usuários é considerada uma das vertentes que compóe o processo de avaliação de políticas públicas. Diante disso, pode-se afirmar que a Ouvidoria serve como ferramenta no processo de avaliação das políticas de saúde.

Uma das competências da Ouvidoria-Geral do SUS é viabilizar e coordenar a realização de estudos e pesquisas visando à produção do conhecimento para subsidiar a formulação de políticas de gestão do SUS. Várias apostas vêm sendo realizadas nas ouvidorias em saúde para esse fim. A Lei Federal 13.460 de 2017 institui processos de avaliação permanente sobre a satisfação dos usuários dos serviços públicos no Brasil e induz uma definição normativa para o Sistema de Ouvidorias descentralizadas do SUS.

As pesquisas de satisfação do usuário são uma das principais ferramentas para a materialização dessa política. A execução desse tipo de pesquisa na Ouvidoria fica a cargo do Nupe. O núcleo agrega a sua dinâmica institucional novas formas de contato ativo, direto e sistemático para coleta de informaçóes a partir do ponto de vista do público destinatário dos serviços de saúde. Atua permanentemente na produção de conhecimento e criação de informação que possibilita o monitoramento e avaliação de políticas de saúde pelos gestores do sistema, além de proporcionar uma análise do processo de mediação formal entre as necessidades dos usuários e as autoridades sanitárias expressa por meio dos canais de participação que permitem sua manifestação (SÁ et al., 2019).

A Carta SUS também é utilizada para a realização de pesquisas de satisfação. As respostas à Carta são utilizadas como subsídio para a pesquisa de satisfação dos usuários do SUS, o que torna possível um melhor conhecimento das expectativas da população em relação aos serviços públicos. Em 2015, a pesquisa de satisfação utilizando dados de 298.473 cartóes-resposta da Carta SUS indicou um alto nível de satisfação com o SUS, assim como a pesquisa de 2016, realizada a partir de 21.309 cartóes-resposta da Carta SUS. Esses dados estáo apresentados abaixo.

Sobre os Hospitais:

- Avaliação das instalaçôes físicas do hospital: muito bom (2015: 47,28\%; 2016 : $46,91 \%)$ 
- Avaliação da equipe de enfermagem: muito bom (2015: 59,90\%; 2016: 62,90\%)

- Avaliaçáo da equipe médica: muito bom (2015: 68,01\%; 2016: 71,02\%)

- Avaliação da maneira como foi tratado: muito bom (2015: 63,09\%; 2016: 65,45\%)

- Você recomendaria o hospital para um amigo ou familiar? Sim (2015: 93\%; 2016: 92,70\%)

Sobre as Unidades de Saúde:

- Avaliação das instalações físicas da unidade de saúde: muito bom (2015: 51,95\%; 2016: 52,62\%)

- Avaliação dos profissionais de saúde que realizaram o tratamento: muito bom (2015: 65,50\%; 2016: 68,68\%)

- Avaliação da maneira como foi tratado: muito bom (2015: 63,58\%; 2016: 65,75\%)

- Você recomendaria a unidade de saúde para um amigo ou familiar? Sim (2015: 96\%; 2016: 96,49\%)

O uso contínuo das ouvidorias influencia na compreensão de usuários, profissionais e gestores sobre o papel desses órgãos, no que se refere principalmente a ser um mecanismo de participaçáo social que estabelece a possibilidade de monitoramento continuado das políticas possibilitando avaliação e controle das mesmas. Nessa perspectiva, destaca-se que não basta criar canais de acesso para manifestaçóes. São necessárias outras iniciativas, como a ouvidoria ativa, por meio da qual é possível produzir estratégias de escuta dos usuários e a realização de busca ativa de informaçóes (PINTO et al., 2015) para uma efetiva incidência no processo das políticas públicas.

\section{Conclusões}

No Brasil, com o processo de democratização surge uma nova acepçáo para o conceito de cidadania: com o cidadáo cada vez mais se percebendo participe do processo de construção de mudança, tornando-se também mais exigente e trazendo consigo uma nova percepção da condução da administração pública. Esse novo padrão de comportamento traz consigo a exigência de novas práticas e experiências de democracia que tenham a participação da sociedade evidenciada de forma clara e direta. 
A presente análise evidenciou que existe no SUS um grande número de canais disponíveis para a participação da cidadania por meio da ouvidoria. Esses canais se adequam à realidade atual, que transforma os canais remotos nas formas de atendimento mais utilizadas. Percebe-se, ainda, que com o passar do tempo a participação dos cidadáos-usuários no SUS via ouvidoria vem aumentando e consolidando-se.

Observou-se ainda que é possível exercer controle social das políticas públicas de saúde por meio da Ouvidoria-Geral do SUS. Instrumentos como o Carta SUS, a Lei de Acesso a Informação e manifestações de tipo "denúncia” possibilitam que o usuário possa ter acesso a dados referentes a políticas do seu interesse e, dessa forma, possa atuar na fiscalização dos processos públicos e seus resultados.

A satisfação do usuário quanto a políticas e serviços públicos é a vertente da avaliação possível via Ouvidoria-Geral do SUS, mas que parece ser a menos fomentada. Apenas metade relatórios analisados mostraram resultados referentes à satisfação, demonstrado descontinuidade de açôes nesse sentido ou não priorização de açóes nesse sentido. Como exemplo, vimos que durante alguns períodos analisados utilizaram-se mecanismos como a interrompida Carta SUS para realizar atividades de ouvidoria ativa, com o intuito de chegar à opiniâo do usuário com relação a equipamentos públicos e serviços prestados.

A democracia é um processo que vai sendo aprimorado aos poucos. Ela não está pronta, mas é construída a cada dia, por meio das mudanças econômica, política e social (VEGA, 2010). Nessa perspectiva, as ouvidorias possuem papel primordial na construção democrática brasileira já que criam canais de participação da cidadania na administração pública, de controle social de gestão e políticas, além de fomentarem o aprimoramento das políticas e serviços públicos.

\section{Referências}

ALVES JUNIOR, M. N. A contribuiçâa estratégica das Ouvidorias para a melhoria dos serviços prestados pelas organizaçóes: um estudo de caso na Secretaria de Estado da Saúde de Santa Catarina (dissertação). Universidade do Estado de Santa Catarina, Florianópolis. 2002.

ANTUNES, L. R. Ouvidorias do SUS no processo de participação social em saúde. Revista Saúde Coletiva, v. 5, n. 26, 238-241. 2008.

ANTUNES, C. K. S.; FREITAS, N. M. de B.; RIBEIRO, J. F. F. Ouvidoria: interrelação entre controle social e controle interno. Espaço Acadêmico da Ouvidoria do IPEA. 2007. 
BRASIL. Ministério da Saúde. Secretaria de Gestão Estratégica e Participativa. Departamento de Ouvidoria-Geral do SUS. Relatório Gerencial de 2016. Brasília. 2017. . Relatório Gerencial de 2015. Brasília. 2016. . Relatório Gerencial de 2014. Brasília. 2015. . Manual das Ouvidorias do SUS. Brasília: 2014a. . Relatório Gerencial de 2013. Brasília. 2014b. . Relatório Gerencial de 2012. Brasília. 2013. . Relatório Gerencial de 2011. Brasília. 2012. . Relatório Gerencial de 2010. Brasília. 2011. . Relatório Gerencial de 2009. Brasília. 2010.

BRASIL. Ministério da Saúde. Manual das Ouvidorias do SUS. Brasília, 2014a.

BRESSER-PEREIRA, L. C. Reflexóes sobre reforma gerencial brasileira de 1995. Revista do Serviço Público, v. 50, n. 4, 5-30. 1999.

ESPERIDIÃO, M. A.; TRAD, L. A. B. Avaliação de satisfação de usuários: consideraçóes teórico- conceituais. Cadernos de Saúde Pública, vol. 22, n. 6, 1267-1276. 2006.

FERNANDES, F. M. B.; MOREIRA, M. R.; RIBEIRO, J. M. Análise da atuação das ouvidorias estaduais do Sistema Único de Saúde como instâncias participativas. Saúde debate, Rio de Janeiro, v. 40, n. spe, p. 201-212, Dec. 2016.

FERNANDEZ, M. V.; GURGEL JUNIOR, G. D.; SÁ, D. A. De; MEDEIROS, K. R. De; CALIARI, R. V. As ouvidorias públicas na democracia brasileira: o caso das ouvidorias do SUS. In SÁ, D. A.; GURGEL JUNIOR, G. D.; FERNANDEZ, M. V.; MOREIRA, R. S. Ouvidoria do SUS: a voz do cidadão e resultados de pesquisas. Recife: Editora UFPE. 2019.

GIL, A. C. Como elaborar projetos de pesquisa. 4. ed. São Paulo: Atlas. 2002.

LüDKE, M.; ANDRÉ, M. E. D. A. Pesquisa em educação: abordagens qualitativas. São Paulo: EPU. 1986.

LYRA, R. P. A ouvidoria pública e a questão da autonomia. In LYRA, R. P. (org.), Participaçáo, democracia e segurança pública. João Pessoa: Editora UFPB. 2008.

LYRA, R. P. A experiência da Universidade Federal da Paraíba e o Instituto da Ouvidoria. Ouvidoria da UFPB. Ouvidoria da UFPB. 2001.

MENEZES, R. do A.; NETO, F. C. L.; CARDOSO, A. S. R. As ouvidorias e o uso público da razão: proposta de um modelo ideal-possível à luz dos atos normativos das Ouvidorias Públicas federais no Brasil. In: Ouvidoria Pública brasileira: reflexóes, avanços e desafios. Orgs.: MENEZES, R. A.; CARDOSO, A. S. R. Brasília: Ipea, 2016. 231 p. 
NETO, F. L.; DÚRAN, P. R. F. Ouvidorias Públicas e Conselhos de Políticas: avanços e desafios na democratização da participação social e nas relaçóes entre estado e sociedade. In: Ouvidoria pública brasileira: reflexóes, avanços e desafios. Orgs.: MENEZES, R. A.; CARDOSO, A. S. R. Brasília: Ipea, 2016.231 p.

PATTON, M. Q. Qualitative evaluation methods. Michigan: Sage Publications. 1980.

PINTO, H; BURILlE, A.; BARBOSA, M.; FERLA, A. Avaliação da Atenção Básica: a ouvidoria ativa como estratégia de fortalecimento do cuidado e da participação social. Saúde em Rede, vol. 1, n. 4, 15-26. 2015.

PNUD. La democracia en América Latina. Hacia una democracia de ciudadanas y ciudadanos. Nueva York: Pnud. 2004.

SÁ, D. A.; GURGELJUNIOR, G. D.; FERNANDEZ, M. V. (org.). Manual para o desenvolvimento de pesquisas na Ouvidoria-Geral do SUS. Recife: Editora Fiocruz. 2019. (No prelo).

SÁ-SILVA, J.; ALMEIDA, C.; GUINDANI, J. Pesquisa documental: pistas teóricas e metodológicas. Revista Brasileira de História \& Ciências Sociais, ano I, n. I, 1-15. 2009.

SANTOS, M. A. C. Controladoria, Ouvidoria e Procuradoria no exercício do controle interno na Administração Pública Estadual Pernambucana. Revista do Centro de Estudos Jurídicos Procuradoria-Geral do Estado de Pernambuco, v.4, n. 4, 74-105. 2011.

SERRA, R. C.; CARVAlHO, J. R.; CARNEIRO, R. Accountability democrático e as ouvidorias. Revista do Tribunal de Contas do estado de Minas Gerais, vol. 30. 2012.

SILVA, R. de C. C. da; PEDROSO, M. C.; ZUCCHI, P. Ouvidorias públicas de saúde: estudo de caso em ouvidoria municipal de saúde. Rev. Saúde Pública, São Paulo, v. 48, n. 1, p. 134-141, Fev. 2014.

VEGA, L. Ouvidoria é democracia. Organicom, v. 7, n. 12. 2010. 


\section{Abstract}

\section{Ombudsman as instrument of participation, control and evaluation of public health policies in Brazil}

The Public Ombudsmen represent a breakthrough in the Brazilian Public Administration, in the democratic management field. In this perspective, this paper aims to analyze the performance of the OmbudsmanGeneral of the Unified Health System. So, how does the Ombudsman-General of the Unified Health System act within the scope of health policies? To answer this question, it was conducted documentary research using management reports from the Department of Ombudsman-General of the Unified Health System of The Brazilian Health Ministry produced between 2010 and 2017. To classify the information, participation, social control and evaluation were used as categories of analysis. It was noted that the participation of citizensusers of Unified Health System via Ombudsman has been increasing and consolidating. The OmbudsmanGeneral of the Unified Health System provides many channels for citizen participation, including telephone and internet which are currently the most accessed forms of participation. Instruments such as the SUS Letter, the Access to Information Law and "whistleblowing" manifestations allow the exercise of social control. User satisfaction is an evaluative aspect that is little promoted, demonstrating discontinuity or devaluation of this kind of action. Thus, in the health field, the ombudsman allow citizen participation, social control and the improvement of policies and services, and it is important to advance further in their development.

> Keywords: Unified Health System Ombudsman, participation, social control, policy evaluation, Unified Health System. 